\title{
Penggunaan Metode TPR Storytelling untuk Mengajarkan Kosakata Bahasa Inggris
}

\author{
Indah Puspawati 1 \\ 1. Pendidikan Bahasa Inggris, Fakultas Pendidikan Bahasa, Universitas Muhammadiyah Yogyakarta \\ Email: indahpuspawati@umy.ac.id \\ DOI: 10.18196/ppm.32.205
}

\begin{abstract}
Abstrak
Kegiatan pengabdian kemitraan masyarakat ini dilaksanakan di SD Muhammadiyah Insan Kreatif Kembaran, Tamantirta, Kasihan, Bantul. Tujuan pelaksanaan kegiatan ini adalah untuk meningkatkan penguasaan kosa kata bahasa Inggris siswa SD tersebut. Pembelajaran Bahasa Inggris kurang variatif. Kurangnya sumber daya untuk memfasilitasi pengajaran Bahasa Inggris merupakan permasalahan yang dihadapi oleh sekolah mitra tersebut. Program kemitraan ini melaksankan program pembelajaran bahasa Inggris dengan metode Total Physical Response (TPR) storytelling. Pengajaran TPR storytelling ini dilaksanakan oleh dosen dibantu oleh mahasiswa PBI UMY sebagai fasilitator pelaksanaan program. Program pengajaran ini telah dilaksanakan secara tatap muka (luring) sebanyak dua kali. Akan tetapi, karena kondisi pandemi yang mengharuskan siswa belajar dari rumah, program ini diubah menjadi pembuatan video pembelajaran dengan menggunakan TPR story telling. Dari pengajaran secara tatap muka, diperoleh hasil bahwa siswa-siswi juga terlihat antusias mengikuti pembelajaran dengan menggunakan metode tersebut. Hal ini terlihat dari antusiasme mereka memeragakan dan menyebutkan kosakata yang diajarkan dengan menggunakan TPR storytelling. Selain itu, penggunaan TPR storytelling bisa membuat siswa-siswi SD memahami kosakata bahasa Inggris lebih cepat. Hal ini terlihat dari kemampuan siswa untuk menyebutkan kembali kosakata yang diajarkan selama menggunakan TPR storytelling. Melihat hasil positif penggunaan metode tersebut, kami menyarankan penggunaan metode TPR storytelling untuk pengajaran Bahasa Inggris.
\end{abstract}

Kata Kunci: Total Physical Response (TPR); storytelling; TPR_storytelling; Vocabulary_Mastery

\section{Pendahuluan}

Pembelajaran Bahasa Inggris di SD Muhammadiyah Insan Kreatif Kembaran dilaksanakan sejak kelas 1 - 6 selama 1 jam pelajaran (jp) 1jp = 35 menit) setiap minggunya. Pembelajaran Bahasa Inggris ini diampu oleh satu orang guru. Berdasarkan wawancara dengan guru pengampu Bahasa Inggris terungkap beberapa permasalahan. Pertama, kegiatan pembelajaran Bahasa Inggris kurang variatif. Hal ini disebabkan untuk pembelajaran Bahasa Inggris, guru harus menggunakan buku teks wajib dan pembelajaran diharuskan sesuai dengan buku teks tersebut. Guru menyatakan bahwa beliau ingin melaksanakan pembelajaran yang menyenangkan, tetapi tuntutan untuk mengikuti buku teks tersebut mengurangi kreativitas guru untuk melaksanakan pembelajaran yang menyenangkan. Permasalahan kedua adalah karena kurang variatifnya pembelajaran Bahasa Inggris. Hal ini menyebabkan minat pembelajaran menjadi menurun. Guru menyatakan bahawa minat Belajar Bahasa Inggris siswa yang mulanya sangat tinggi menjadi menurun. Hal ini ditunjukkan dengan siswa yang ketika kelas 1-4 masih semangat belajar Bahasa Inggris, di kelas 5 dan 6, siswa tersebut menurun semangat belajaranya. Menurut guru pengampu, hal tersebut disebabkan metode pembelajaran yang kurang variatif. Menurunnya semangat belajar bahasa Inggris ini dikhawatirkan akan berimbas kepada menurunnya kemampuan bahasa Inggris siswa.

Oleh karena itu, program kemitraan ini bertujuan untuk menemukan metode pembelajaran yang kreatif yang bisa menciptakan pembelajaran yang menyenangkan dan meningkatkan minat pembelajaran Bahasa Inggris. Metode yang dipilih dalam program ini adalah penggunaan Total Physical Response (TPR) storytelling. Metode TPR storytelling ini dipilih karena banyak penelitian yang sudah membuktikan bahwa metode ini bisa menciptakan pembelajaran yang menyenangkan bagi para siswa SD. Penelitian yang dilaksanakan oleh Fahrurrozi (2017) 
mengenai penggunaan TPR dalam pengajaran kosa kata bahasa Inggris untuk siswa SD membuktikan bahwa TPR diakui sebagai metode pembelajaran yang menarik bagi siswa SD. Penelitian lainnya mengenai penggunaan storytelling oleh Kirsch (2012), Kalantari \& Hashemian (2016), dan Giannikas (2019) juga membuktikan bahwa metode storytelling terbukti bisa menciptakan suasana kelas yang menyenangkan dan bisa meningkatkan semangat siswa dalam pembelajaran. Apabila metode TPR dan storytelling ini digabungkan, hal ini akan memberi dampak yang lebih positif terhadap pembelajaran Bahasa Inggris untuk siswa SD (Rusiana, 2016; Kara \& Eveyik-Aydın, 2019). Beberapa peneitian tindakan kelas membuktikan bahwa siswa SD yang proses pembelajaran menggunakan TPR storytelling terbukti penguasaan kosakata lebih baik daripada siswa yang proses pembelajarannya tidak menggunakan TPR storytelling (Kirsch, 2012; Kalantari \& Hashemian, 2015; Rusiana, 2016; Farizawati, 2016; Fahrurrozi, 2017; dan Kara \& Eveyik-Aydın, 2019). Penggunaan metode pengajaran menggunakan TPR storytelling diharapkan bisa memecahkan masalah yang dihadapi sekolah mitra, yaitu pembelajaran yang kurang menarik dan bisa meningkatkan ketertarikan siswa SD untuk belajar bahasa Inggris.

\section{Metode Pelaksanaan}

Pelaksanaan program ini dibagi menjadi beberapa tahapan. Tahapan persiapan dilaksanakan untuk mempersiapkan materi pembelajaran menggunakan TPR storytelling. Materi pembelajaran yang disiapkan adalah pemilihan cerita pendek yang cocok dengan siswa SD. Selain itu, cerita juga harus mengandung kata-kata yang bisa diajarkan melalui peragaan. Cerita yang dipilih dan digunakan dalam pengajaran yang menggunakan metode TPR storytelling adalah A Little Ant, A Very Hungry Caterpilar, dan Three Little Pigs. Selanjutnya, diadakan pelatihan mahasiswa untuk menjadi fasilitator pengajaran menggunakan metode TPR storytelling.

Tahap berikutnya adalah pelaksanaan program pengajaran di sekolah mitra,. Program ini dilaksanakan kepada siswa-siswi kelas tiga. Pengajaran secara tatap muka dilaksanakan dua kali pertemuan. Dalam hal ini, dosen dan mahasiswa sebagai fasilitator masuk ke kelas untuk mengajar dengan menggunakan metode TPR storytelling. Tahapan mengajar TPR storytelling ini dimulai dari mengenalkan kosakata bahasa Inggris dalam cerita yang diajarkan dengan menggunakan gerakan dan gambar, kemudian dilanjutkan dengan pembacaan cerita sambil siswa memeragakan gerakan ketika kosakata disebutkan dalam cerita. Kegiatan diakhiri dengan mengukur kemampuan siswa dalam memahami kosakata tersebut dengan cara dosen memeragakan gerakan dan siswa menyebutkan kosakata yang dimaksud.

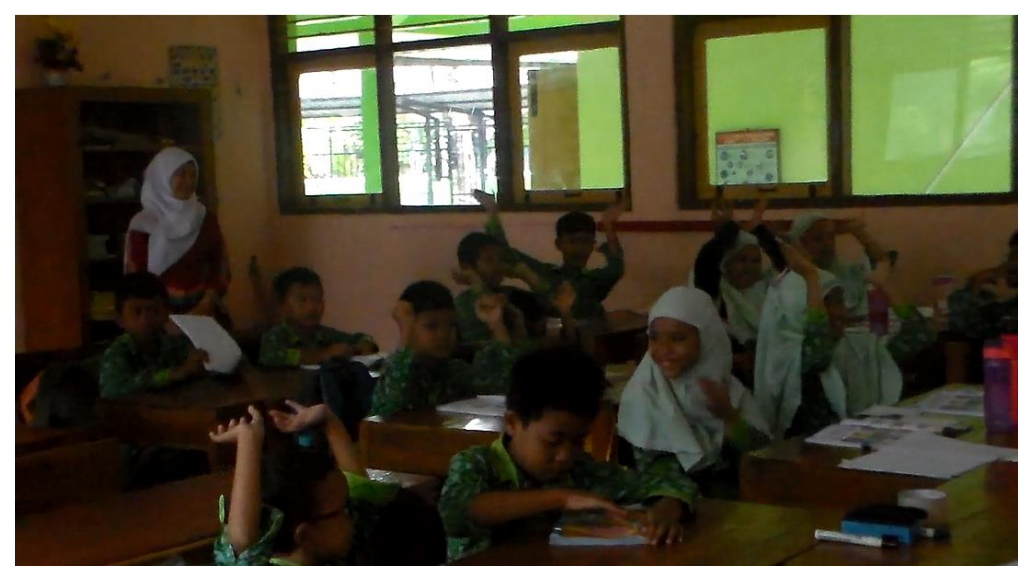




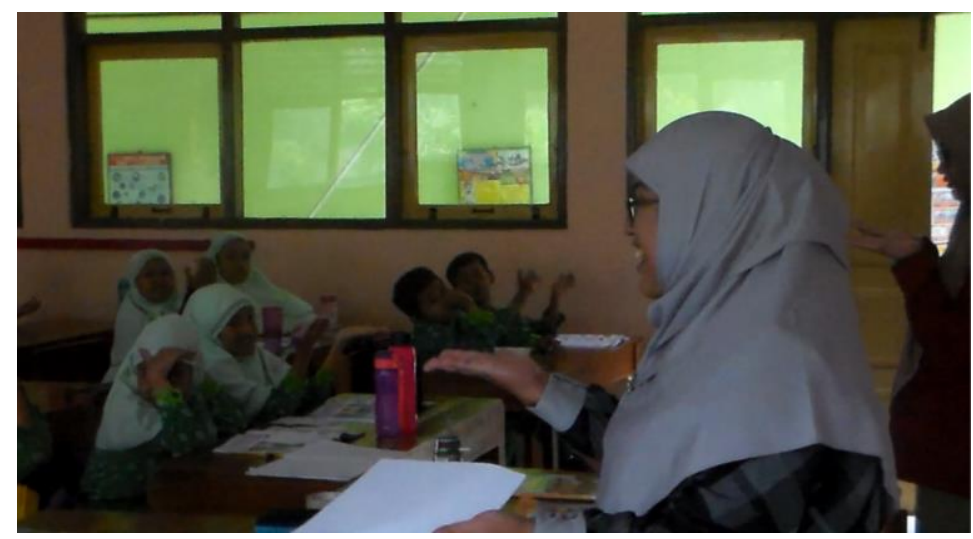

\section{Pengajaran dengan menggunakan metode TPR storytelling}

Tahapan terakhir yang dilaksanakan adalah tahapan pengembangan video pembelajaran dengan menggunakan TPR storytelling. Hal ini dilakukan karena pengajaran tatap muka tidak mungkin lagi dilakukan karena kondisi pandemi yang melanda. Video pembelajaran menggunakan metode ini bisa disimak di https://www.youtube.com/watch?v=jcl04pArlq0 dan https://www.youtube.com/watch?v=vLOBmVPH_L4.
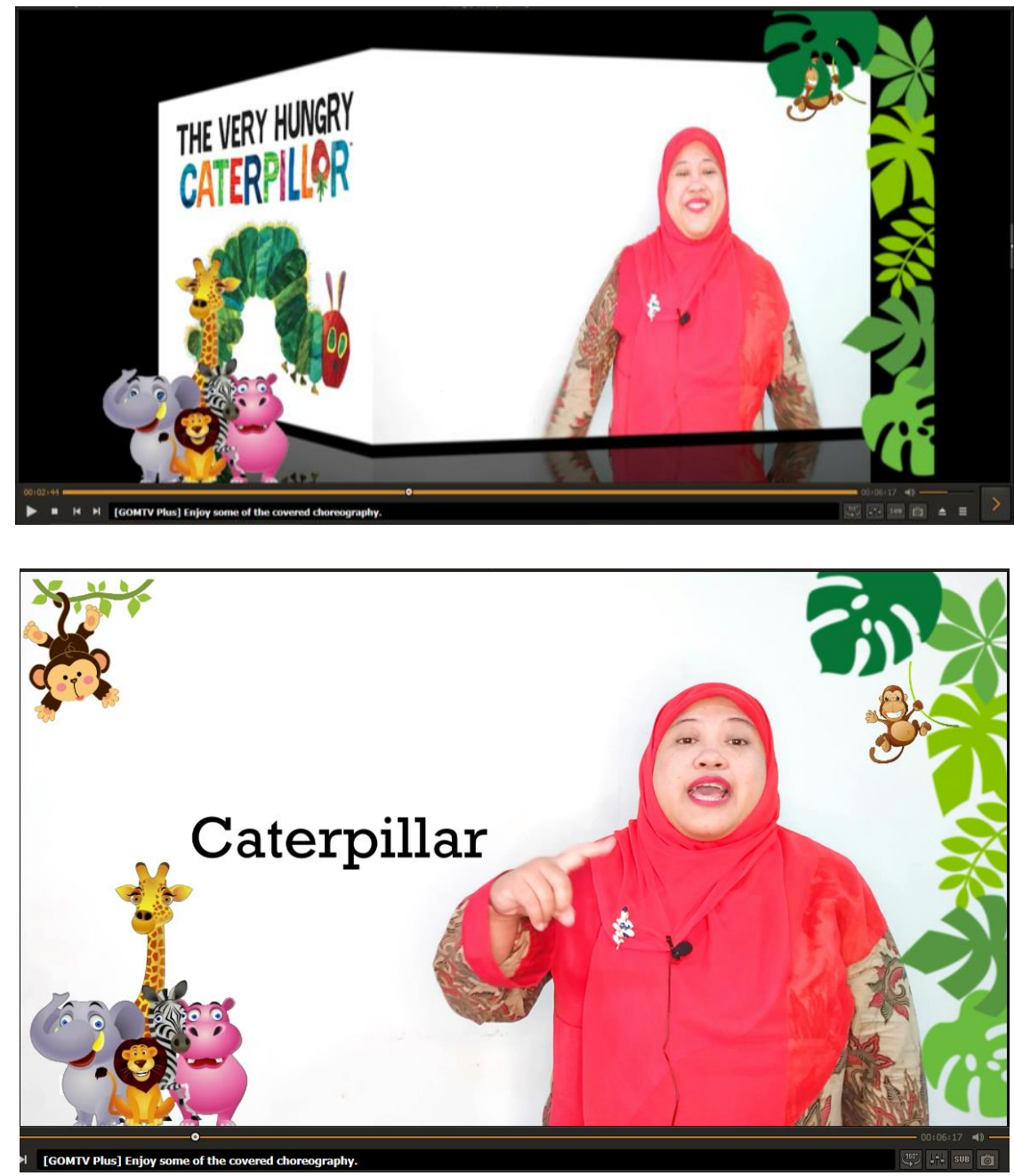

Gambar 2. Video pembelajaran menggunakan TPR storytelling (A Very Hungry Caterpilar) 


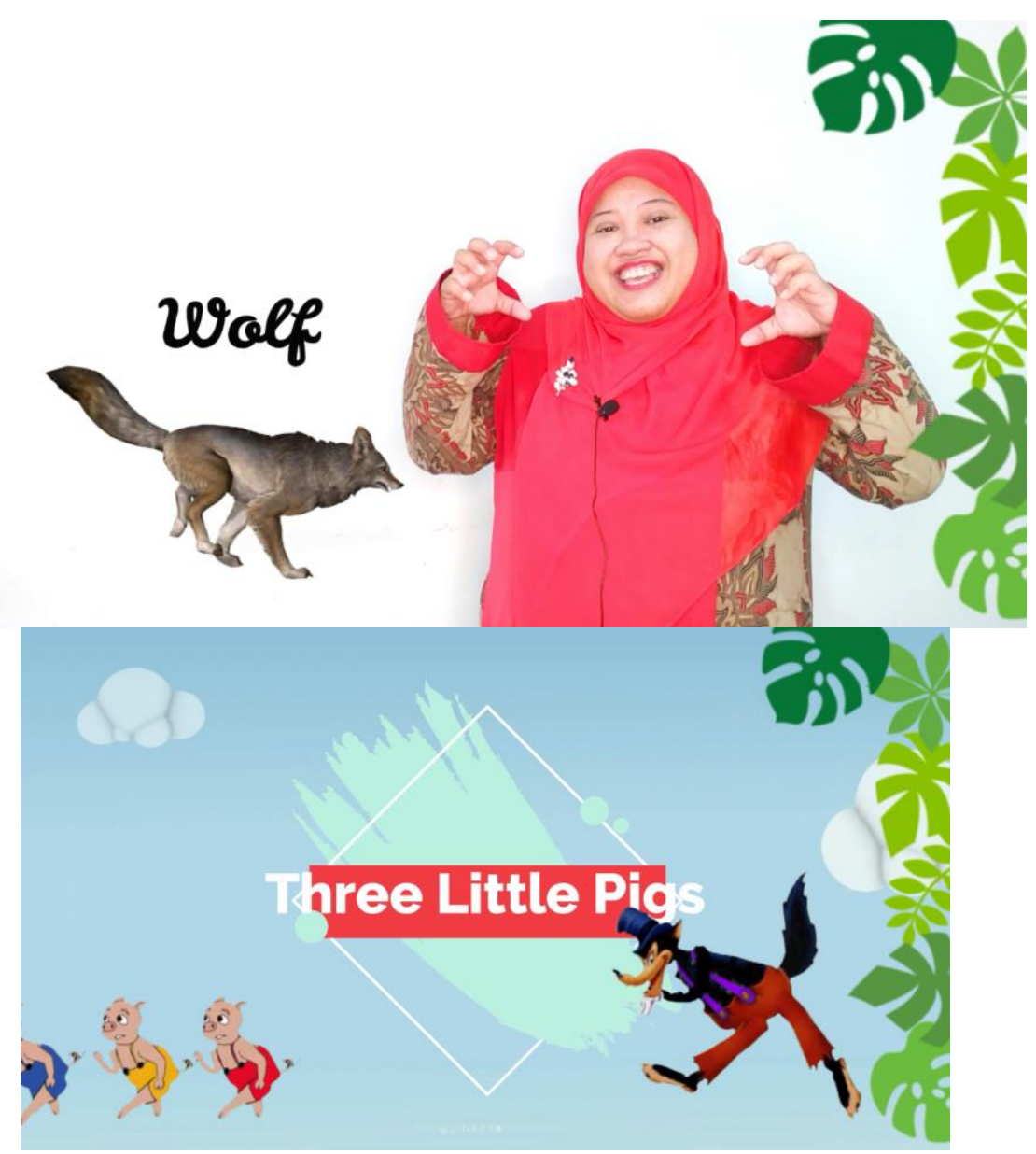

Gambar 3. Video pembelajaran menggunakan TPR storytelling (Three Little Pigs)

\section{Hasil dan Pembahasan}

Program kemitraan masyarakat ini bertujuan untuk memperkenalkan pembelajaran Bahasa Inggris yang menarik dan bisa mengajarkan kosakata bahasa Inggris kepada siswa-siswi SD Muhammadiyah Kreatif Kembaran. Pengukuran keberhasilan program ini dilakukan melalui observasi. Observasi dilakukan pada saat pelaksanaan program dan dilakukan oleh dosen dan mahasiswa sebagai fasilitator. Dari observasi tersebut diperoleh beberapa informasi yang bisa menjadi tolok ukur pencapaian program ini. Hasil pertama yang bisa diobservasi ketika pembelajaran di kelas dengan menggunakan TPR storytelling adalah suasana kelas menjadi lebih dinamis. Hal ini bisa dilihat dari antusiasme siswa-siswi SD tersebut untuk mengikuti pembelajaran. Mereka dengan gembira menirukan gerakan-gerakan untuk mempelajari kosakata tersebut, mulai dari pengenalan kosakata, pembacaan cerita, sampai review kosakata setelah cerita dibacakan. Selain itu, siswa-siswi tersebut juga mendengarkan dengan seksama ketika cerita dibacakan. Hal ini menunjukkan bahwa metode TPR storytelling ini bisa menciptakan suasana pembelajaran yang menarik bagi siswa-siswi SD tersebut. Ini disebabkan metode ini memang cocok dengan karakteristik siswa-siswi SD yang menyukai pembelajaran dengan melibatkan aktivitas fisik karena mereka akan cepat bosan dalam belajar apabila mereka hanya diminta diam mendengarkan penjelasan dari guru. Selain itu, penggunaan cerita sebagai media 
pembelajaran dalam metode ini dapat mengembangkan imaginasi siswa (Rusiana, 2016) sehingga siswa lebih tertarik untuk mengikuti pembelajaran. Dari segi pembelajaran bahasa asing, siswa bisa mendapatkan contoh penggunaan bahasa melalui cerita tersebut. Contoh ini berperan sangat penting dalam perkembangan kompetensi bahasa para siswa (Lichtman, 2018). Selain itu, penggunaan metode ini menuntut siswa harus menirukan gerakan-gerakan untuk mengenal kosakata. Hal ini bisa dianggap siswa sebagai metode belajar sambil bermain (Kara \& Eveyik, 2019). Oleh karena itu, siswa menjadi antusias mengikuti pembelajaran dengan bermain ini karena bermain adalah kegiatan yang disukai oleh siswa-siswi seusia mereka.

Informasi kedua yang bisa diamati dari penerapan penggunaan metode TPR storytelling dalam pembelajaran Bahasa Inggris adalah bahwa metode ini bisa memfasilitasi pembelajaran kosakata. Hal ini bisa dilihat ketika tahap memperkenalkan kosakata di awal pembelajaran, siswa-siswi tersebut belum memahami beberapa kosakata yang terdapat dalam cerita tersebut. Akan tetapi, pada saat tahapan review di akhir cerita, siswa-siswi tersebut bisa menyebutkan semua kosakata yang dipelajari menggunakan metode TPR storytelling. Hal ini membuktikan bahwa metode tersebut bisa memfasilitasi pemahaman kosakata dengan baik karena para ahli pemerolehan bahasa mengemukakan bahwa bahasa itu bisa diperoleh melalui tindakan dan gerakan fisik (Kara \& Eveyik, 2019). Gerakan yang dilakukan ketika mempelajari kosakata mengaktifkan kerja otak kanan yang sangat dibutuhkan oleh siswa dalam belajar Bahasa. Gerakan-gerakan ini bisa membuat siswa mengingat kosakata tersebut secara cepat dan untuk jangka waktu yang lama (Kara \& Eveyik, 2019). Selain itu, Fahrurrozi (2017) juga menyatakan bahwa penggunaan gerakan fisik dalam metode TPR storytelling bisa lebih memudahkan siswa memahami makna kosakata yang dipelajari sehingga siswa bisa lebih memahami dan menambah kosakata bahasa Inggris.

Karena peraturan pemerintah untuk belajar dari rumah selama masa pandemi Covid-19, penggunaan metode pembelajaran TPR storytelling secara tatap muka tidak bisa lagi dilaksanakan. Oleh karena itu, pembuatan video pembelajaran menggunakan metode tersebut dijadikan salah satu pilihan untuk meneruskan pelaksanaan program ini. Dua video pembelajaran menggunakan metode tersebut sudah dibuat untuk memfasilitasi pembelajaran daring yang diterapkan tersebut. Video pembelajaran ini dirancang agar siswa-siswi tersebut tetap bisa belajar kosakata bahasa Inggris dengan cara yang menyenangkan. Akan tetapi, karena semua pihak (siswa, guru, dan tim pengabdian) saat itu sedang beradaptasi dengan sistem pembelajaran daring, video tersebut belum bisa dimanfaatkan dengan baik. Selain itu, tantangan pengajaran menggunakan metode ini secara daring adalah memastikan bahwa siswa benar-benar menirukan gerakan-gerakan dalam video pembelajaran tersebut. Akan tetapi, video pembelajaran tersebut diharapkan tetap bisa menyajikan pembelajaran Bahasa Inggris secara menyenangkan meskipun pembelajaran dilakukan secara daring.

Melihat efek positif dari penggunaan metode TPR storytelling ini terhadap siswa-siswi kelas tiga SD Muhammadiyah Insan Kreatif Kembaran, metode ini direkomendasikan untuk digunakan dalam pengajaran Bahasa Inggris untuk siswa SD. Namun, ada beberapa hal yang perlu diperhatikan dalam penerapan metode ini agar penerapannya bisa lebih efektif. Pertama, kosakata yang diajarkan dalam metode ini harus dalam jumlah yang tidak terlalu banyak karena siswa bisa mengalami kesulitan dan merasa bosan bila kosakata yang diajarkan terlalu banyak. Kedua, metode ini hanya bisa mengajarkan kosakata yang tidak abstrak dan bisa diperagakan sehingga metode ini tidak harus menjadi satu-satunya metode yang digunakan dalam pembelajaran. Terakhir, penggunaan metode ini harus direncanakan secara cermat supaya siswa 
tidak akan hanya belajar memahami arti kosakata tetapi juga bisa menggunakan kosakata tersebut dalam kalimat atau percakapan.

\section{Simpulan}

Penggunaan metode TPR storytelling untuk mengenalkan kosakata bahasa Inggris untuk siswa-siswi SD bisa membuat pembelajaran lebih menarik karena pada saat pembelajaran siswa mendengarkan cerita. Hal ini merupakan salah satu kegiatan yang disukai oleh siswa-siswi tersebut. Selain itu, metode ini mengharuskan siswa untuk aktif mengikuti gerakan untuk belajar kosakata bahasa Inggris. Aktivitas ini juga bisa membantu siswa mengingat kosakata lebih cepat. Hal ini bisa dilihat dari kemampuan mereka menyebutkan kosakata yang diajarkan selama penggunaan metode TPR storytelling. Oleh karena itu, metode ini terbukti bisa mempercepat siswa-siswa SD untuk mengingat kosakata bahasa Inggris.

\section{Ucapan Terima Kasih}

Kami mengucapkan terima kasih kepada LP3M UMY dan SD Muhammadiyah Insan Kreatif Kembaran yang telah memfasilitasi pelaksanaan program kemitraan ini. Kami juga mengucapkan terima kasih kepada mahasiswa PBI UMY yang telah membantu terlaksanakannya program ini.

\section{Daftar Pustaka}

Fahrurrozi. (2017). Improving students' vocabulary mastery by Using Total Physical Response. English Language Teaching, 10(3), 118-127.

Kirsch, C. (2012). Using storytelling to teach vocabulary in language lessons: Does it work?, The Language Learning Journal, 44(1), 33-51

Kalantari, F., \& Hashemian, M. (2016). A story-telling approach to teaching English to young EFL Iranian Learners. English Language Teaching, 9(1), 221-234.

Giannikas, C.N. (2019). Language education and primary school children: The story of using stories. International Journal of Action Research, 2019(2), 157-169.

Rusiana. (2016). Improving students' vocabulary mastery through TPR Storytelling. Indonesian Journal of English Language Teaching and Applied Linguistics, 1(1), 49-61.

Kara, K. \& Eveyik-Aydın, E. (2019). Effects of TPRS on very young learners' vocabulary acquisition. Advances in Language and Literary Studies. 135-146.

Farizawati. (2016). Using storytelling for teaching vocabulary. English Education Journal, 7(2), 246-259.

Lichtman, K. (2018). Teaching proficiency through Reading and Storytelling (TPRS): An inputbased approach to second language instruction. New York: Routledge. 